\title{
Increased frequency of regulatory $T$ cells in the peripheral blood of patients with endometrioid adenocarcinoma
}

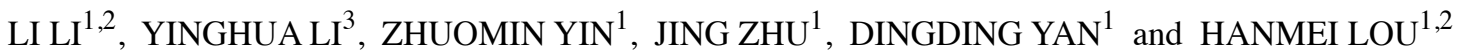 \\ ${ }^{1}$ Department of Gynecologic Oncology, Zhejiang Cancer Hospital; \\ ${ }^{2}$ Key Laboratory of Radiation Oncology of Zhejiang Province, Hangzhou, Zhejiang 310022; \\ ${ }^{3}$ Women's Hospital, School of Medicine, Zhejiang University, Hangzhou, Zhejiang 310006, P.R. China
}

Received April 14, 2018; Accepted April 5, 2019

DOI: $10.3892 / \mathrm{ol} .2019 .10452$

\begin{abstract}
The aim of the present study was to investigate the frequency of cluster of differentiation (CD) $4^{+} \mathrm{CD} 25^{+} \mathrm{CD} 127^{-}$ regulatory $\mathrm{T}$ cells (Tregs) in the peripheral blood mononuclear cells (PBMCs) of patients with endometrioid adenocarcinoma (EA). A total of 82 female patients with EA were recruited. The PBMCs were flow cytometrically analyzed to determine the percentage of $\mathrm{CD} 4^{+} \mathrm{CD} 25^{+} \mathrm{CD} 127^{-}$Tregs within the $\mathrm{CD} 4^{+}$ $\mathrm{T}$ cell population. The associations between the prevalence of Tregs in PBMCs and defined clinical prognostic parameters were evaluated. To study the immunoregulatory capacity of Tregs, the level of specific cytokines were detected by ELISA, and the proliferation of cells was analyzed by incorporation of ${ }^{3} \mathrm{H}$-thymidine. It was revealed that Treg/CD $4^{+}$ratio in the peripheral blood of patients with EA was $4.89 \pm 1.42 \%$, significantly higher than Treg/CD4 ${ }^{+}$ratio in healthy women. No correlation was observed between Treg frequency and stage, grade of differentiation, menopausal status or age. $\mathrm{CD} 4^{+} \mathrm{CD} 25^{+} \mathrm{CD} 127^{-}$Tregs secreted large amounts of IL-10 but not IFN- $\gamma$. The level of IL-10 secreted by Tregs from patients with EA and healthy controls was not significantly different. In addition, there was no significant difference in the suppressive activity of Tregs in patients with EA compared with that of the healthy controls. These findings demonstrate that the increased frequency of immunosuppressive Tregs in patients with EA may be responsible for immune tolerance in endometrial cancer.
\end{abstract}

\footnotetext{
Correspondence to: Professor Hanmei Lou, Department of Gynecologic Oncology, Zhejiang Cancer Hospital, 1 East Banshan Road, Gongshu, Hangzhou, Zhejiang 310022, P.R. China

E-mail: zjhzlouhanmei@sina.com
}

Abbreviations: Tregs, regulatory $\mathrm{T}$ cells; EA, endometrioid adenocarcinoma

Key words: Treg cells, endometrial cancer, endometrioid adenocarcinoma, peripheral blood, interleukin-10

\section{Introduction}

In China, endometrial cancer is one of the most common malignant carcinomas of the female reproductive organs, and its incidence has steadily increased (1). The vast majority of endometrial cancer cases are endometrioid adenocarcinoma (EA) cases $(2,3)$. This type of uterine cancer forms in the glandular cells of the uterine lining (2). EA is commonly detected early and has a high cure rate $(4,5)$. A number of risk factors are involved in the etiology of endometrial cancer, including obesity, diabetes and ageing of the population (6). It is believed that tumorigenesis results from cell growth dysregulation and the failure of the host to provide a sufficient antitumor immune response (7). The immune system, which is markedly influenced by age and certain hormones, has been reported to be associated with the development and progression of endometrial cancer (6). Immune cells, including tumor-associated macrophages, cluster of differentiation $(\mathrm{CD}) 8^{+}$cytotoxic T cells, natural killer (NK) cells, $\mathrm{CD}^{+} \mathrm{T}$ helper cells and dendritic cells (DCs) constitute an important part of the microenvironment and are thought to be critical for endometrial cancer development and progression (6). However, the precise mechanisms by which the immune system is modulated in patients with endometrial cancer remain poorly understood.

Regulatory T cells (Tregs), characterized by the co-expression of CD4 and CD25, have been revealed to suppress $\mathrm{T}$ cell-mediated host immune responses against self- and non-self-antigens (8-10). The transcription factor Forkhead box protein P3 (FOXP3) is considered to be one of the most specific markers of Tregs. Evidence has confirmed that Tregs are involved in the immune tolerance of malignant neoplasms, as they suppress immune responses by cytokine secretion and direct contact (11). Increased levels of Tregs have been reported at tumor sites, draining lymph nodes and in the peripheral blood in many kinds of human cancer, including breast, colon, lung, prostate, liver, ovarian cancer and hematological malignancies (12-16). An increased level of Tregs in human cancer is considered to be a poor prognostic factor. Studies have attempted to reduce the number of Tregs in order to control cancer in experimental models; Turk et al (17) demonstrated enhanced tumor immunity in mouse models by depletion of Tregs. 
Some researchers have reported the presence of Tregs in the tumor tissue, peripheral blood and tumor draining lymph nodes of patients with endometrial cancer (18-21). High levels of intratumoral were revealed to associate with poorer disease-free survival, increased grade of differentiation, cancer stage, the extent of lymph node metastases and myometrial invasion $(18,20)$. The mechanisms underlying Treg enrichment in patients with endometrial cancer are not clear; the proportion and the role of Tregs in the peripheral blood of patients with endometrial cancer is still ambiguous and controversial, as a limited number of small studies have been reported $(18,21)$. The increased number of Tregs in the peripheral blood of patients might be responsible for suppressing anti-tumor immunity.

In the present study, to elucidate the role of Tregs in EA, the frequencies and suppressive functions of Tregs in the peripheral blood of patients with EA and healthy controls were evaluated. The association between the frequency of Tregs in the peripheral blood of patients with EA and certain clinical prognostic parameters was also analyzed.

\section{Materials and methods}

Study participants. The present study was approved by the Ethical Committee of Zhejiang Cancer Hospital (Hangzhou, China). Written informed consent was obtained from all participants. The current study included a total of 82 female patients with EA who were admitted to the Department of Gynecologic Oncology at Zhejiang Cancer Hospital between August 2012 and June 2015, in addition to 30 healthy women who were recruited during routine health checkups at Zhejiang Cancer Hospital, enrolled as the controls. The age range of the patients with EA was 30-70 years, while the age range of the healthy controls was 31-69 years. All patients with EA were diagnosed by endometrial biopsy prior to recruitment. At the recruitment stage, none of the patients had received chemotherapy, radiotherapy or any other previous medical intervention. Prior to surgery, $20 \mathrm{ml}$ heparinized peripheral venous blood was obtained, and the patients with EA underwent subsequent staging surgery; the surgical specimens were examined by experienced pathologists. Clinical and pathological parameters, including age, menopausal status, stage, grade of differentiation, lymphatic or vascular permeation and lymph node metastatic status were evaluated for each patient. The surgical staging of EA was performed according to the International Federation of Gynecology and Obstetrics (FIGO) classification (22). None of the participants had received hormonal or immunosuppressant therapy for $\geq 6$ months prior to staging. A total of $20 \mathrm{ml}$ heparinized peripheral venous blood was also obtained from healthy controls.

Flow cytometry. A total of $20 \mathrm{ml}$ peripheral venous blood was collected from each participant into sterile heparinized container. Peripheral blood mononuclear cells (PBMCs) were isolated by Ficoll-Hypaque (GE Healthcare Life Sciences, Uppsala, Sweden) density gradient separation for $30 \mathrm{~min}$ at $800 \mathrm{x} \mathrm{g}$ at $20^{\circ} \mathrm{C}$. The PBMCs were washed twice in PBS and then resuspended in PBS at $1 \times 10^{6}$ cells $/ \mathrm{ml}$ for further analysis. PBMCs were analyzed by flow cytometry for the phenotypic characterization of Tregs. In brief, PBMCs were
Table I. Percentage of $\mathrm{CD} 4^{+} \mathrm{CD} 25^{+} \mathrm{CD} 127^{-}$Tregs within the $\mathrm{CD} 4^{+}$cell population in the peripheral blood.

$\mathrm{CD} 4{ }^{+} \mathrm{CD} 25^{+} \mathrm{CD} 127$

Group Tregs/CD4 $4^{+} \mathrm{T}$ cells $(\%)$

Endometrioid adenocarcinoma $(\mathrm{n}=82) \quad 4.89 \pm 1.42^{\mathrm{a}}$

Healthy controls $(n=30)$

$3.34 \pm 0.84$

${ }^{\mathrm{a}} \mathrm{P}=0.019$ vs. healthy controls. $\mathrm{CD}$, cluster of differentiation; Treg, regulatory $\mathrm{T}$ cell.

incubated with specific antibodies (1:10 dilution; mouse anti-human, monoclonal; Beckman Coulter, Brea, CA, USA) against phycoerythrin-cyanine 5-conjugated anti-CD4 (cat. no. A07752), fluorescein isothiocyanate-conjugated anti-CD25 (cat. no. IM0478U) and phycoerythrin-conjugated anti-CD127 (cat. no. IM1980 U), or isotype controls (1:10 dilution; IgG1-FITC, cat. no. A07795; and IgG1-PE, cat. no. A07796; Beckman Coulter), in the dark for $30 \mathrm{~min}$ at $20^{\circ} \mathrm{C}$. Subsequently, a washing step was performed using PBS. For blocking, cells were suspended in $0.2 \%(\mathrm{w} / \mathrm{v}) \mathrm{BSA}$ (cat. no. 554657; BD Biosciences, San Jose, CA, USA) with Human BD Fc Block ${ }^{\mathrm{TM}}$ (cat. no. 564220; BD Biosciences) for $10 \mathrm{~min}$ at $20^{\circ} \mathrm{C}$. Data from $1 \times 10^{5}$ cells/sample were acquired using the FC500 flow cytometer (Beckman Coulter, Brea, CA, USA) and analyzed with Win 7 CXP version 2.2 software (Beckman Coulter). To determine the relative ratio of Tregs, the $\mathrm{CD}^{+}$ population was gated, followed by the $\mathrm{CD} 25^{+} \mathrm{CD} 127^{-}$population. FOXP3 is widely accepted as the most reliable marker for Tregs, thus validation experiments were performed by intracellular FOXP3 staining with the Anti-Human Foxp3 Staining Set APC kit (cat. no. 77-5776-40; eBioscience; Thermo Fisher Scientific, Inc., Waltham, MA, USA) according to the manufacturer's protocol; $\mathrm{CD} 4^{+} \mathrm{CD} 25^{+} \mathrm{CD} 127^{-}$cells with high expression of FOXP3 (>90\%) were confirmed.

Cell culture, cytokine and proliferation assays. PBMCs from the peripheral venous blood of patients with EA and healthy controls were isolated by Ficoll-Hypaque density gradient separation. $\mathrm{CD} 4^{+} \mathrm{CD} 25^{+} \mathrm{CD} 127^{-}$Tregs and $\mathrm{CD} 4^{+} \mathrm{CD} 25^{-} \mathrm{T}$ cells were purified with the MACS CD4 Multisort kit (cat. no. 130-055-101), CD25 (cat. no. 130-092-983) and CD127 (cat. no. 130-094-945) Microbeads (Miltenyi Biotec, Auburn, CA, USA) using magnetic separation columns, according to the manufacturer's protocol. The purities of the enriched cells were $>92 \%$ (determined by flow cytometry). Purified $\mathrm{CD} 4^{+} \mathrm{CD} 25^{+} \mathrm{CD} 127^{-}$Tregs and $\mathrm{CD} 4^{+} \mathrm{CD} 25^{-} \mathrm{T}$ cells $\left(1 \times 10^{5}\right.$ cells) were placed on anti-CD3 mAb (10 ng/ml; cat. no. M725429-2; DAKO; Agilent Technologies, Inc., Santa Clara, CA, USA)-coated 96-well flat-bottomed plates and cultured in $200 \mu 1$ AIM-V medium (Thermo Fisher Scientific, Inc.) at $37^{\circ} \mathrm{C}$ for $24 \mathrm{~h} . \mathrm{CD}^{+} \mathrm{CD} 25^{+} \mathrm{CD} 127^{-}$Tregs and $\mathrm{CD} 4^{+} \mathrm{CD} 25^{-} \mathrm{T}$ cells were stimulated with immobilized anti-CD3 mAbs. The supernatants were harvested and the level of IFN- $\gamma$ and IL-10 production was detected using the Human IFN- $\gamma$ Quantikine ELISA kit (cat. no. DIF50; R\&D Systems, Inc., Minneapolis MN, USA) and the Human IL-10 Quantikine 


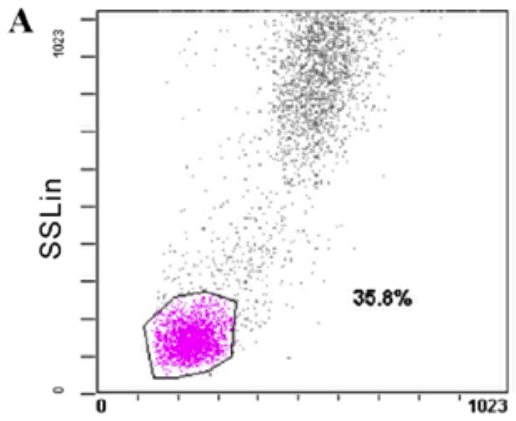

FS Lin

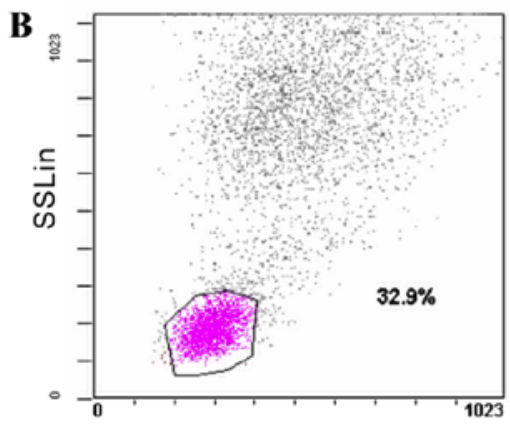

FS Lin

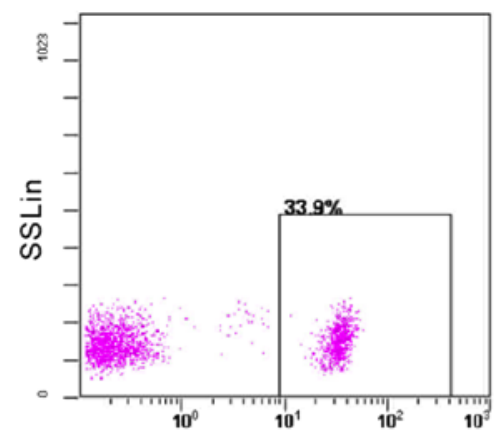

CD4-PC5

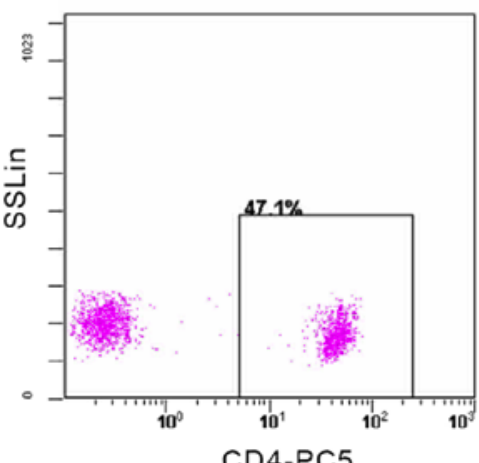

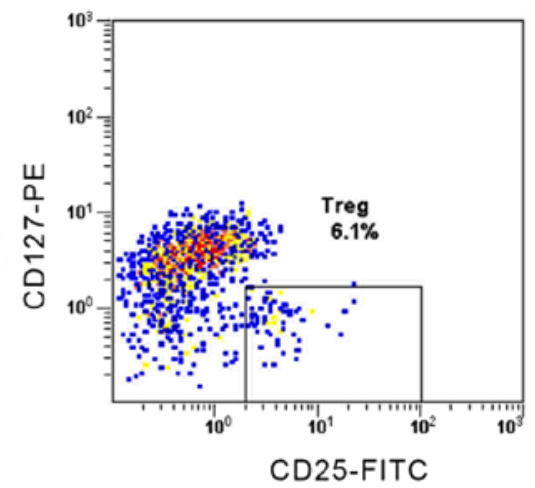

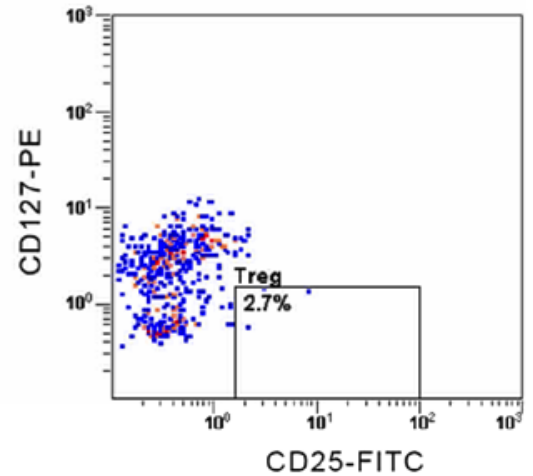

Figure 1. Flow cytometry. The percentage of CD4+CD25+CD127- Tregs within the CD4+ T cell population in the peripheral blood was detected by flow cytometry. (A) The percentage of CD4+CD25+CD127- Tregs within the CD4+ T cell population in the peripheral blood of one patient with endometrioid adenocarcinoma was $6.1 \%$. (B) The percentage of CD4+CD25+CD127- Tregs within the CD4+ T cell population in the peripheral blood of one healthy woman was $2.7 \%$. CD, cluster of differentiation; Treg, regulatory T cell; PC5, phycoerythrin-cyanine 5; FITC, fluorescein isothiocyanate; PE, phycoerythrin.

ELISA kit (cat. no. D1000B; R\&D Systems, Inc.), according to the manufacturer's protocols. Subsequently, the anti-proliferative function of $\mathrm{CD} 4^{+} \mathrm{CD} 25^{+} \mathrm{CD} 127^{-}$Tregs was assessed by evaluating the proliferative activity of $\mathrm{CD} 4^{+} \mathrm{CD} 25^{-} \mathrm{T}$ cells in response to anti-CD3 plus anti-CD28 antibodies, in the presence of autologous $\mathrm{CD} 4{ }^{+} \mathrm{CD} 25^{+} \mathrm{CD} 127$ cells. Briefly, purified $\mathrm{CD} 4^{+} \mathrm{CD} 25^{+} \mathrm{CD} 127^{-}$Tregs were incubated with autologous CD4 ${ }^{+} \mathrm{CD} 25^{-} \mathrm{T}$ cells $\left(1 \times 10^{5}\right.$ cells each) on anti-CD3 $\mathrm{mAb}$ $(10 \mathrm{ng} / \mathrm{ml})$-coated 96 -well round-bottomed plates in the presence of an anti-CD28 mAb $(10 \mu \mathrm{g} / \mathrm{ml}$; cat. no. 555726; BD Biosciences) for $72 \mathrm{~h}$. Proliferation was measured by incorporation of ${ }^{3} \mathrm{H}$-thymidine $(10 \mathrm{uCi} / \mathrm{ml})$. Cells were harvested after $16 \mathrm{~h}$ and thymidine incorporation was measured using a scintillation counter and expressed as counts per minutes.

Statistical analysis. All data were expressed as the mean \pm standard deviation. All experiments were performed at least three times. Comparisons between two groups were analyzed using the Student's t-test for normally distributed variables. ANOVA followed by Bonferroni correction was performed for more than two groups of data. Spearman's rank correlation coefficient test was used to analyze the association between clinical prognostic parameters and Treg frequency. $\mathrm{P}<0.05$ was considered to indicate a statistically significant difference. Analyses were performed using SPSS version 16.0 (SPSS, Inc., Chicago, IL, USA).

\section{Results}

Clinical characteristics. All endometrial cancer cases were classified as EA. The mean age of the patients with EA was
$53.65 \pm 7.06$ years, whilst the mean age of healthy controls was $51.58 \pm 6.83$ years; though this difference was not significant. A total of 28 patients with EA were $<50$ years old, while the other 54 patients were $\geq 50$ years old. Among the 82 patients, 22 were premenopausal and 60 were postmenopausal.

Increased Treg/CD4 ${ }^{+}$ratio in the peripheral blood of patients with $\mathrm{EA}$. The $\mathrm{CD} 4^{+} \mathrm{CD} 25^{+} \mathrm{CD} 127^{-} \mathrm{Treg} / \mathrm{CD} 4^{+}$ratio in the peripheral blood of patients with EA was $4.89 \pm 1.42 \%$, significantly higher compared with that in healthy controls (3.34 \pm 0.84 ; $\mathrm{P}=0.019$; Table I). Representative flow cytometry plots illustrate the percentage of Tregs in both groups (Fig. 1). As presented in Table II, no significant difference in $\mathrm{CD} 4{ }^{+} \mathrm{CD} 25^{+} \mathrm{CD} 127^{-}$Treg frequency was observed among patients with EA in association with tumor stage $(\mathrm{P}=0.753)$ or differentiation grade $(\mathrm{P}=0.686)$. As endometrial cancer occurs predominantly in postmenopausal women (23), 82 patients with EA were divided into postmenopausal $(\mathrm{n}=60)$ and premenopausal $(n=22)$ groups; no significant difference in $\mathrm{CD} 4{ }^{+} \mathrm{CD} 25^{+} \mathrm{CD} 127^{-}$Treg frequency was observed in association with menopausal status $(\mathrm{P}=0.581)$. As the majority of women reach the menopause at $\sim 50$ years of age (1), $\mathrm{CD} 4^{+} \mathrm{CD} 25^{+} \mathrm{CD} 127^{-}$Treg frequency between EA patients $<50$ years-old and those $\geq 50$ years-old was compared; no significant difference was observed $(\mathrm{P}=0.667)$. No association between Treg frequency and tumor stage, grade of differentiation, menopausal status or age was observed.

Cytokines produced by $\mathrm{CD} 4^{+} \mathrm{CD} 25^{+} \mathrm{CD} 127^{-}$Tregs. As illustrated in Fig. 2, CD $4{ }^{+} \mathrm{CD} 25^{+} \mathrm{CD} 127^{-}$Tregs derived from 
Table II. Association between Treg frequency and clinicopathological factors.

\begin{tabular}{lcc}
\hline $\begin{array}{l}\text { Clinicopathological } \\
\text { factor }\end{array}$ & $\begin{array}{c}\text { CD4 }{ }^{+} \mathrm{CD} 25^{+} \mathrm{CD} 127^{-} \\
\text {Tregs/CD4 }\end{array}$ & \\
\hline Stag cells $(\%)$ & P-value \\
I (n=59) & & 0.753 \\
II (n=8) & $4.90 \pm 1.45$ & \\
III (n=15) & $4.88 \pm 1.47$ & \\
Grade & $4.88 \pm 1.45$ & 0.686 \\
G1 (n=17) & & \\
G2 (n=42) & $4.89 \pm 1.46$ & \\
G3 (n=23) & $4.89 \pm 1.45$ & \\
Menopausal status & $4.91 \pm 1.41$ & \\
Premenopausal $(\mathrm{n}=22)$ & & \\
Postmenopausal $(\mathrm{n}=60)$ & $4.87 \pm 1.43$ & \\
Age, years & $4.90 \pm 1.46$ & \\
$<50$ (n=28) & & \\
$\geq 50$ (n=54) & $4.86 \pm 1.43$ & \\
\hline
\end{tabular}

$\mathrm{CD}$, cluster of differentiation; Treg, regulatory $\mathrm{T}$ cell.

patients with EA produced little IFN- $\gamma$, but large amounts of IL-10. CD $4^{+} \mathrm{CD} 25^{-} \mathrm{T}$ cells derived from both groups secreted large amounts of IFN- $\gamma$ but notably less IL-10. Similarly, $\mathrm{CD} 4{ }^{+} \mathrm{CD} 25^{+} \mathrm{CD} 127^{-}$Tregs derived from healthy controls secreted little IFN- $\gamma$, but large amounts of IL-10. There was no significant difference in IL-10 secretion by Tregs between the two groups $(\mathrm{P}=0.274)$.

Treg suppression assays. As presented in Fig. 3, it was confirmed that $\mathrm{CD} 4^{+} \mathrm{CD} 25^{+} \mathrm{CD} 127^{-}$Tregs markedly suppress the proliferation of $\mathrm{CD}^{+} \mathrm{CD} 25^{-} \mathrm{T}$ cells. However, no significant difference was observed in the suppressive activity of Tregs between patients with EA (suppressive efficacy, 38\%; Fig. 3A) and healthy controls (suppressive efficacy, 32\%; Fig. 3B; $\mathrm{P}=0.196)$.

\section{Discussion}

The present study indicated that patients with EA have increased Treg frequencies in their peripheral blood compared with healthy controls. In line with a previous study (15), a significantly increased $\mathrm{CD} 4^{+} \mathrm{CD} 25^{+} \mathrm{CD} 127^{-} \mathrm{Treg} / \mathrm{CD} 4^{+}$ratio in the peripheral blood of patients with EA with a suppressive function was revealed. These $\mathrm{CD} 4{ }^{+} \mathrm{CD} 25^{+} \mathrm{CD} 127^{-}$Tregs produced high levels of IL-10 and suppressed the proliferation of $\mathrm{CD} 4^{+} \mathrm{CD} 25^{-} \mathrm{T}$ cells. However, there was no correlation with Treg frequency in association with stage, histological grading, menopausal status and age, which was in contrast to other studies $(18,21)$.

FOXP3 is considered as the most specific marker for Tregs and is co-expressed with CD4 and CD25 (24). However, another study has reported that intracellular FOXP3 staining may cause cell damage (25), thus the $\mathrm{CD} 4^{+} \mathrm{CD} 25^{+} \mathrm{CD} 127^{-}$phenotype has been proposed as an alternative to identify Tregs in clinical samples. In the present study, it was confirmed that $\mathrm{CD} 4^{+} \mathrm{CD} 25^{+} \mathrm{CD} 127^{-}$cells may be recognized as a highly purified population of $\mathrm{FOXP}^{+}$Tregs.

However, in the present study, no correlation between Treg frequency and stage, histological grade, menopausal status or age was observed. Notably, some contrasting results were revealed when compared with other similar studies. It is widely accepted that tumor stage, grade of differentiation and myometrial invasion are independent prognostic factors for endometrial cancer. Chang et al (18) reported that the high prevalence of $\mathrm{CD} 4{ }^{+} \mathrm{CD} 25^{+}$Tregs in the cancer stroma and in the peripheral blood of 57 patients with endometrial cancer was closely associated with clinical features, including tumor grade, stage, lymph node metastasis and myometrium invasion. Sawan et al (26) revealed an increased proportion of Tregs in the peripheral blood of 24 patients with endometrial cancer, which may have been attributed to their postmenopausal status or age, but not with cancer stage or grade. The lack of agreement among researchers on the associations between the Treg frequency in the peripheral blood and clinical prognostic parameters may be attributed to different cancer types and/or different sample sizes. In the present study, all of the 82 samples collected were EA, whilst patients with non-endometrioid adenocarcinoma (NEA) were excluded. Different mechanisms are involved in the pathogenesis of EA and NEA $(3,27)$. It was therefore hypothesized that the inhibition of the immune response in patients with endometrial cancers may be influenced by several inhibitory mechanisms, including the number of Tregs in the peripheral blood, the tumor microenvironment and the cancer type.

The association between age and circulating Tregs in humans has been investigated in numerous studies (26,28-30), and the function of Tregs is thought to be age-dependent (25). However, there is conflicting evidence as to whether Treg frequency in the peripheral blood increases with age or not $(29,30)$. A number of studies concerning Tregs in the peripheral blood of patients with cancer did not investigate the association between age and Treg frequency, and more studies did not report the age of the control group $(11,12,15,31)$. Although others provided this data, the healthy controls were significantly younger compared with patients $(26,28-30)$. A lack of age-matched controls in such studies may mean that their results may be misleading. The present study investigated the effect of aging on Treg frequency by analyzing the correlation between age and Treg frequency; the mean age of patients with EA was similar to the healthy controls, and the difference was not significant. As endometrial cancer usually occurs in postmenopausal women (23), and women in China predominantly reach the menopause at $\sim 50$ years of age (1), $\mathrm{CD} 4{ }^{+} \mathrm{CD} 25^{+} \mathrm{CD} 127^{-}$Treg frequency between EA patients $<50$ years old and those $\geq 50$ years old was compared; however, no statistically significant difference was observed. Therefore, differences in Treg frequency between patients with EA and healthy women were not associated with age.

To the best of our knowledge, there has been only one study (21) regarding the role of menopause in Treg frequency or function in patients with EA. Menopause is characterized by cessation of ovarian functions, including hormonal 

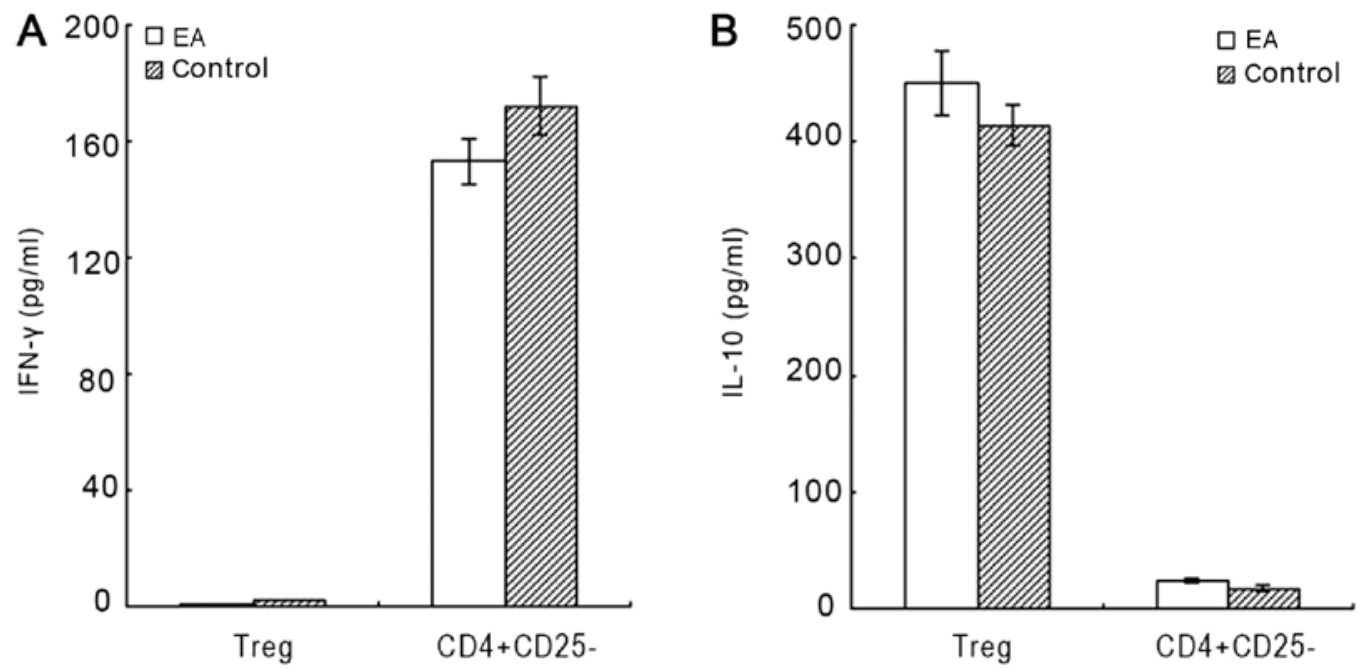

Figure 2. Cytokine production assay. $\mathrm{CD} 4^{+} \mathrm{CD} 25^{+} \mathrm{CD} 127^{-}$Tregs and $\mathrm{CD} 4^{+} \mathrm{CD} 25^{-} \mathrm{T}$ cells isolated from the peripheral blood of patients with EA and healthy controls were stimulated with immobilized anti-CD3 monoclonal antibodies respectively, and their supernatants were assessed by ELISA for IFN- $\gamma$ and IL-10. (A) $\mathrm{CD} 4^{+} \mathrm{CD} 25^{+} \mathrm{CD} 127^{-}$Tregs derived from patients with EA or healthy women did not produce IFN- $\gamma$, whilst the CD4+CD25- T cells of both groups secreted IFN- $\gamma$. There was no difference in the level of IFN- $\gamma$ production in $\mathrm{CD}^{+}{ }^{+} \mathrm{CD} 25^{-} \mathrm{T}$ cells between patients with EA and healthy controls. (B) $\mathrm{CD} 44^{+} \mathrm{CD} 25^{+} \mathrm{CD} 127$ Tregs derived from patients with EA produced large amounts of IL-10. Similarly, CD4 ${ }^{+} \mathrm{CD} 25^{+} \mathrm{CD} 127^{-}$Tregs derived from healthy women produced large amounts of IL-10. There was no difference in the level of IL-10 production of Tregs between patients with EA and healthy controls. CD4 $4^{+} \mathrm{CD} 25^{-} \mathrm{T}$ cells from both groups secreted little IL-10. There was no difference in the level of IL-10 production of CD4+ ${ }^{+} \mathrm{CD} 25^{-} \mathrm{T}$ cells between patients with EA and healthy controls. EA, endometrioid adenocarcinoma; CD, cluster of differentiation; Treg, regulatory T cell; IFN, interferon, IL-10, interleukin-10.
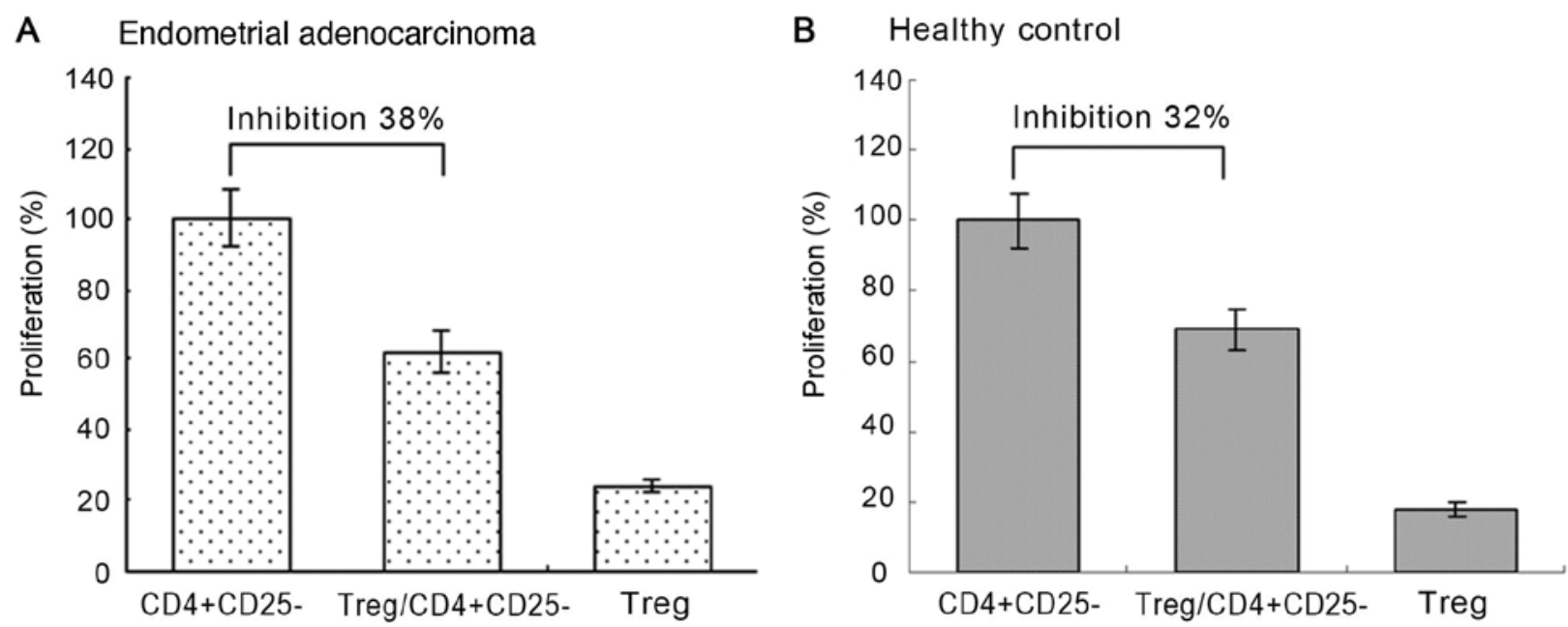

Figure 3. Cell proliferation assay. Purified $\mathrm{CD} 4{ }^{+} \mathrm{CD} 25^{+} \mathrm{CD} 127^{-}$Tregs isolated from the peripheral blood of patients with EA and healthy controls were incubated with autologous $\mathrm{CD} 4^{+} \mathrm{CD} 25^{-} \mathrm{T}$ cells (ratio of 1:1) and cell proliferation was measured in triplicate cultures by ${ }^{3} \mathrm{H}$-thymidine incorporation. The proliferation of $\mathrm{CD} 4^{+} \mathrm{CD} 25^{-} \mathrm{T}$ cells alone, or $\mathrm{CD} 4^{+} \mathrm{CD} 25^{+} \mathrm{CD} 127^{-}$Tregs alone was also measured. The proliferation of $\mathrm{CD} 4^{+} \mathrm{CD} 25^{-} \mathrm{T}$ cells was considered to be $100 \%$. The isolated $\mathrm{CD} 4^{+} \mathrm{CD} 25^{+} \mathrm{CD} 127^{-}$Tregs notably decreased the proliferation of $\mathrm{CD} 4^{+} \mathrm{CD} 25^{-} \mathrm{T}$ cells; though there was no difference in the suppressive activity of Tregs between (A) patients with EA and (B) healthy controls. EA, endometrioid adenocarcinoma; CD, cluster of differentiation; Treg, regulatory T cell.

release, representing the end of a woman's reproductive life. The majority of cases of endometrial cancer are diagnosed in post-menopausal patients when blood estrogen levels are low, and $>80 \%$ of cases are EA $(6,27)$. Increased exposure to estrogen is considered to be an important risk factor of EA, and previous studies $(32,33)$ have reported that Treg frequency changed during the menstrual cycle; the number of Tregs increased in the proliferative phase when compared with that in the secretory phase $(32,33)$. In addition, estrogen has been reported to induce Treg proliferation in vitro (1). In the present study, a higher proportion of patients with EA were postmenopausal. However, there was no association between
Treg frequency in the peripheral blood and menopausal status in either patients with EA or in healthy women. Therefore, the observed difference in Treg frequency between patients with EA and healthy women did not appear to associate with menopausal status. These findings were in contradiction to a previous study (21). In order to investigate the true association between EA and Treg frequency, a larger cohort of patients is required with appropriately matched controls.

IFN- $\gamma$ is an inflammatory cytokine that can exhibit direct cytotoxic and cytostatic activity toward tumor cells, and inhibits the peripheral induction of naive $\mathrm{CD} 4^{+} \mathrm{T}$ cells to FOXP3 ${ }^{+}$Tregs $(34,35)$. IL-10, a cytokine produced by Tregs, 
can directly and indirectly inhibit effector $\mathrm{T}$ cell responses in cancer (36-38). It is suggested that IL-10 production by Tregs may mediate immune suppression in the human tumor microenvironment. Tumor-derived Tregs are reported to suppress DC function by producing IL-10 (39). The results of the present study suggest that Tregs produced large amounts of IL-10, confirming their suppressive activity. Tumorigenesis is correlated with increased prevalence of Tregs in the peripheral blood (8). Previous studies have reported that Tregs suppress the antigen presentation function of DCs, the proliferation and activation of $\mathrm{CD}^{+} \mathrm{T}$ cells, $\mathrm{CD} 4^{+} \mathrm{T}$ cells, NK cells and NKT cells $(11,40,41)$. In patients with melanoma, Tregs can regulate tumor-specific $\mathrm{CD}^{+} \mathrm{T}$ cell responses. Therefore, it was hypothesized that increased Treg frequency in patients with EA may be responsible for impaired cellular immunity. It was revealed that $\mathrm{CD} 4^{+} \mathrm{CD} 25^{+} \mathrm{CD} 127^{-}$Tregs suppress the proliferation of $\mathrm{CD}^{+} \mathrm{CD} 25^{-} \mathrm{T}$ cells, which subsequently confirmed that $\mathrm{CD} 4^{+} \mathrm{CD} 25^{+} \mathrm{CD} 127^{-}$Tregs isolated from patients with EA suppressed the $\mathrm{T}$ cell response. However, the level of IL-10 secreted by Tregs from patients and healthy controls was not significantly different. There was also no significant difference in the suppressive activity of Tregs between patients and healthy controls. It was therefore concluded that the suppressive function of Tregs might be relatively stable in different situations, though the number of Tregs alters in patients with EA, which may influence the regulation of the antitumor immune response by direct and indirect contact with other immune cells.

In conclusion, an increased frequency of Tregs with suppressive function in patients with EA may serve a role in regulating the antitumor immune response. However, no correlation between Treg frequency and tumor stage, differentiation grade, menopausal status or age was observed. As peripheral Tregs may be recruited to tumor sites and proliferate as a result of self-antigen recognition by memory Tregs, it may be more informative to monitor tumor-infiltrating Tregs in patients with EA, rather than circulating Tregs.

\section{Acknowledgements}

Not applicable.

\section{Funding}

The present study was supported by the Zhejiang Provincial Natural Science Foundation of China (grant no.LQ18H160019), the Zhejiang Provincial Medical Science and Technology Plan (grant no. 2016KYA035) and the Zhejiang Provincial Science and Technology Planning Project for Chinese Medicine (grant no. 2016ZA040).

\section{Availability of data and materials}

The datasets used and/or analyzed during the present study are available from the corresponding author on reasonable request.

\section{Authors' contributions}

LL and HL contributed to the conception of this study and performed the preliminary experiments. All authors participated in the design of the study and implemented the research. DY and
LL enrolled participants in the study and collected clinical data. JZ performed the flow cytometry experiments. LL, YL, ZY and JZ determined cytokine levels and cell proliferation. All authors participated in the statistical analysis and contributed to the interpretation of the results as well as the writing of the study. All authors reviewed all data and approved the final manuscript.

\section{Ethics approval and consent to participate}

This study followed international and national regulations in accordance with the Declaration of Helsinki. The present study was approved by the Ethical Committee of Zhejiang Cancer Hospital (Hangzhou, China). Written informed consent was obtained from all participants.

\section{Patient consent for publication}

Not applicable.

\section{Competing interests}

The authors declare that they have no competing interests.

\section{References}

1. Li L, Wu J, Pu D, Zhao Y, Wan C, Sun L, Shen C, Sun W, Yuan Z, Shen Q, et al: Factors associated with the age of natural menopause and menopausal symptoms in Chinese women. Maturitas 73: 354-360, 2012.

2. Siegel RL, Miller KD and Jemal A: Cancer statistics, 2019. CA Cancer J Clin 69: 7-34, 2019.

3. Murali R, Soslow RA and Weigelt B: Classification of endometrial carcinoma: More than two types. Lancet Oncol 15: e268-e278, 2014.

4. Fung-Kee-Fung M, Dodge J, Elit L, Lukka H, Chambers A and Oliver T; Cancer Care Ontario Program in Evidence-based Care Gynecology Cancer Disease Site: Follow-up after primary therapy for endometrial cancer: A systematic review. Gynecol Oncol 101: 520-529, 2006.

5. LajerH,Elnegaard S, Christensen RD, Ortoft G, Schledermann DE and Mogensen O: Survival after stage IA endometrial cancer; can follow-up be altered? A prospective nationwide Danish survey. Acta Obstet Gynecol Scand 91: 976-982, 2012.

6. Vanderstraeten A, Tuyaerts S and Amant F: The immune system in the normal endometrium and implications for endometrial cancer development. J Reprod Immunol 109: 7-16, 2015.

7. Grivennikov SI, Greten FR and Karin M: Immunity, inflammation and cancer. Cell 140: 883-899, 2010.

8. Sakaguchi S, Miyara M, Costantino CM and Hafler DA: FOXP3+ regulatory $\mathrm{T}$ cells in the human immune system. Nat Rev Immunol 10: 490-500, 2010.

9. Wing K and Sakaguchi S: Regulatory T cells exert checks and balances on selftolerance and autoimmunity. Nat Immunol 11: 7-13, 2010.

10. Shevach EM: Mechanisms of foxp3+ T regulatory cell-mediated suppression. Immunity 30: 636-645, 2009.

11. Beyer $M$ and Schultze JL: Regulatory $T$ cells in cancer. Blood 108: 804-811, 2006.

12. Miller AM, Lundberg K, Ozenci V, Banham AH, Hellstrom M, Egevad L and Pisa P: CD4+CD25high T cells are enriched in the tumor and peripheral blood of prostate cancer patients. J Immunol 177: 7398-7405, 2006.

13. Perez SA, Karamouzis MV, Skarlos DV, Ardavanis A, Sotiriadou NN, Iliopoulou EG, Salagianni ML, Orphanos G, Baxevanis CN, Rigatos G and Papamichail M: CD4+CD25+ Regulatory T-cell frequency in HER-2/neu (HER)-positive and HER-negative advanced-stage breast cancer patients. Clin Cancer Res 13: 2714-2721, 2007.

14. Hanagiri T, Shigematsu Y, Shinohara S, Takenaka M, Oka S, Chikaishi Y, Nagata Y, Iwata T, Uramoto H, So T and Tanaka F: Clinical significance of the frequency of regulatory $\mathrm{T}$ cells in regional lymph node lymphocytes as a prognostic factor for non-small-cell lung cancer. Lung Cancer 81: 475-479, 2013. 
15. Sellitto A, Galizia G, De Fanis U, Lieto E, Zamboli A Orditura M, De Vita F, Giunta R, Lucivero G and Romano C: Behavior of circulating CD4+CD25+Foxp3+ regulatory t cells in colon cancer patients undergoing surgery. J Clin Immunol 31: 1095-1104, 2011.

16. Wertel I, Surówka J, Polak G, Barczyński B, Bednarek W, Jakubowicz-Gil J, Bojarska-Junak $A$ and Kotarski J: Macrophage-derived chemokine CCL22 and regulatory T cells in ovarian cancer patients. Tumour Biol 36: 4811-4817, 2015.

17. Turk MJ, Guevara-Patiño JA, Rizzuto GA, Engelhorn ME Sakaguchi S and Houghton AN: Concomitant tumor immunity to a poorly immunogenic melanoma is prevented by regulatory $\mathrm{T}$ cells. J Exp Med 200: 771-782, 2004.

18. Chang WC, Li CH, Huang SC, Chang DY, Chou LY and Sheu BC: Clinical significance of regulatory $\mathrm{T}$ cells and CD8+ effector populations in patients with human endometrial carcinoma. Cancer 116: 5777-5788, 2010

19. Fattorossi A, Battaglia A, Ferrandina G, Buzzonetti A, Legge F Salutari V and Scambia G: Lymphocyte composition of tumor draining lymph nodes from cervical and endometrial cancer patients. Gynecol Oncol 92: 106-115, 2004.

20. YamagamiW,Susumu N,TanakaH,Hirasawa A,BannoK,SuzukiN Tsuda H, Tsukazaki K and Aoki D: Immunofluorescence-detected infiltration of CD4+FOXP3+ regulatory t cells is relevant to the prognosis of patients with endometrial cancer. Int J Gynecol Cancer 21: 1628-1634, 2011.

21. Sawan S, Burt DJ, Stern PL, Holland C and Elkord E: Circulating regulatory $\mathrm{T}$ cells in endometrial cancer: A role for age and menopausal status. Immunol Invest 40: 62-75, 2011.

22. Creasman W: Revised FIGO staging for carcinoma of the endometrium. Int J Gynaecol Obstet 105: 109, 2009.

23. Kong A, Johnson N, Kitchener HC and Lawrie TA: Adjuvant radiotherapy for stage I endometrial cancer: An updated cochrane systematic review and meta-analysis. J Natl Cancer Inst 104: 1625-1634, 2012.

24. Hori S, Nomura T and Sakaguchi S: Control of regulatory T cell development by the transcription factor Foxp3. Science 299: 1057-1061,2003.

25. Liu W,Putnam AL, Xu-Yu Z,Szot GL,Lee MR,Zhu S, GottliebPA Kapranov P, Gingeras TR, Fazekas de St Groth B, et al: CD127 expression inversely correlates with FoxP3 and suppressive function of human CD4+ T reg cells. J Exp Med 203: 1701-1711, 2006.

26. Sawan S, Burt DJ, Stern PL, Holland C and Elkord E: Circulating regulatory $\mathrm{T}$ cells in endometrial cancer: A role for age and menopausal status. Immunol Invest 40: 62-75, 2011.

27. Morice P, Leary A, Creutzberg C, Abu-Rustum N and Darai E: Endometrial cancer. Lancet 387: 1094-1108, 2016.

28. Tsaknaridis L, Spencer L, Culbertson N, Hicks K, LaTocha D, Chou YK, Whitham RH, Bakke A, Jones RE, Offner H, et al: Functional assay for human CD4+CD25+ Treg cells reveals an age-dependent loss of suppressive activity. J Neurosci Res 74: 296-308, 2003
29. Santner-Nanan B, Seddiki N, Zhu E, Quent V, Kelleher A, Fazekas de St Groth B and Nanan R: Accelerated age-dependent transition of human regulatory $\mathrm{T}$ cells to effector memory phenotype. Int Immunol 20: 375-383, 2008.

30. Dejaco C, Duftner C and Schirmer M: Are regulatory T-cells linked with aging? Exper Gerontol 41: 339-345, 2006.

31. Yao X, Ahmadzadeh M, Lu YC, Liewehr DJ, Dudley ME, Liu F, Schrump DS, Steinberg SM, Rosenberg SA and Robbins PF: Levels of peripheral CD4(+)Foxp3(+) regulatory T cells are negatively associated with clinical response to adoptive immunotherapy of human cancer. Blood 119: 5688-5696, 2012.

32. Arruvito L, Sanz M, Banham AH and Fainboim L: Expansion of CD4+CD25+ and FOXP3+ regulatory $\mathrm{T}$ cells during the follicular phase of the menstrual cycle: Implications for human reproduction. J Immunol 178: 2572-2578, 2007.

33. El-Hamarneh T, Hey-Cunningham AJ, Berbic M, Al-Jefout M, Fraser IS and Black K: Cellular immune environment in endometrial polyps. Fertil Steril 100: 1364-1372, 2013.

34. Murphy KM, Ouyang W, Szabo SJ, Jacobson NG, Guler ML, Gorham JD, Gubler U and Murphy TL: T helper differentiation proceeds through Stat1-dependent, Stat4-dependent and Stat4-independent phases. Curr Top Microbiol Immunol 238: 13-26, 1999.

35. Caretto D, Katzman SD, Villarino AV, Gallo E and Abbas AK: Cutting edge: The Th1 response inhibits the generation of peripheral regulatory T cells. J Immunol 184: 30-34, 2010.

36. Asseman C, Mauze S, Leach MW, Coffman RL and Powrie F: An essential role for interleukin 10 in the function of regulatory T cells that inhibit intestinal inflammation. J Exp Med 190: 995-1004, 1999.

37. Belkaid Y, Piccirillo CA, Mendez S, Shevach EM and Sacks DL: CD4+CD25+ regulatory T cells control Leishmania major persistence and immunity. Nature 420: 502-507, 2002.

38. Loser K, Apelt J, Voskort M, Mohaupt M, Balkow S, Schwarz T, Grabbe S and Beissert S: IL-10 controls ultraviolet-induced carcinogenesis in mice. J Immunol 179: 365-371, 2007.

39. Larmonier N, Marron M, Zeng Y, Cantrell J, Romanoski A, Sepassi M, Thompson S, Chen X, Andreansky S and Katsanis E: Tumor-derived CD4(+)CD25(+) regulatory T cell suppression of dendritic cell function involves TGF-beta and IL-10. Cancer Immunol Immunother 56: 48-59, 2007.

40. Vieweg J, Su Z, Dahm P and Kusmartsev S: Reversal of tumor-mediated immunosuppression. Clin Cancer Res 13: 727s-732s, 2007.

41. Nishikawa $\mathrm{H}$ and Sakaguchi S: Regulatory $\mathrm{T}$ cells in cancer immunotherapy. Curr Opin Immunol 27: 1-7, 2014. 